\title{
EDUCATION AND TRAINING RESOURCES ON DIGITAL PHOTOGRAMMETRY
}

\author{
G. Tucci*, A. Conti, L. Fiorini, F. Panighini, E. I. Parisi
}

\begin{abstract}
Dept. of Civil and Environmental Engineering (DICEA), University of Florence, Via di S. Marta 3, 50139 Florence Italy (grazia.tucci@unifi.it, arch.a.conti@gmail.com, lidia.fiorini@gmail.com, francesca.panighini@gmail.com, ericaisabella.parisi@unifi.it)
\end{abstract}

\section{Commission V, WG V/1}

KEY WORDS: Photogrammetry Learning, Education, 3-D data, Interdisciplinarity, Video

\begin{abstract}
:
Current close-range photogrammetry makes it possible to obtain 3-D models from imagery acquired with off-the-shelf digital cameras or other low-cost devices and processed with affordable software or apps in an almost automatic way. For this reason, a wider and wider public (often without a specific training, as archaeologists, architects, landscape planners, digital artists) is using these tools and their outcomes in many fields. However, the drawback of its ease of use is that photogrammetry is often used without any critical awareness of the metric quality of the results.

Therefore, it is necessary to bridge the growing gap between the spread of photogrammetric techniques and their use through appropriate educational processes. The paper presents and explain the results of the project "Education and training resources on digital photogrammetry", financed in 2018 by ISPRS as part of the "Educational and Capacity Building Initiative" programme.

The project, after evaluating the current teaching methodologies and techniques, is producing and sharing original teaching materials (like videos and datasets) on digital photogrammetry. The aim is to transform the traditional transmissive didactic model in a newer one in which the students have an active role and improve their proficiencies solving actual case studies in practice. This induces students to rethink and better understand all the steps of the photogrammetric project design, acquisition and processing but above all to acquire greater skills to critically evaluate the acquired data and results.
\end{abstract}

\section{INTRODUCTION}

Digital photogrammetry plays a key role in digitization programmes of built heritage, artifacts, landscape, etc. and it is no longer an exclusive prerogative of specialists but interests a wider audience, due to the possibility of obtaining 3-D models of real-world objects from photographs taken by ordinary cameras and automatically (or almost automatically) processed with free or low-cost software.

Photogrammetry is already considered by many people one of the available tools for both professional and amateur applications, but this has a risk: it is so easy to use that many are exploiting it without any critical awareness on the metric quality of the results.

For this reason, it is important that students and users are made aware of the factors that allow them to obtain correct photogrammetric projects.

\section{GEOMATICS IN OUR POCKETS}

Although often without being aware of this, many people habitually use instruments and techniques created for geomatic applications. The modern smartphones and devices have sophisticated sensors like digital cameras, GPS receivers, gyroscopes, magnetometers and accelerometers used for positioning, navigation, data recording and transmission in a transparent and unwitting way. Even if they are not professional grade tools, they can be effectively used to teach science and geomatics to youngest students (Teo et al. 2014).
Since many years it has been pointed out that such data can be used for the documentation of cultural heritage, both by using, for example, the photos that countless unaware users have shared on the Internet (Agarwal et al., 2011), both by stimulating the curiosity and active participation of the population for projects on recording and documentation of cultural heritage (Letellier, 2015).

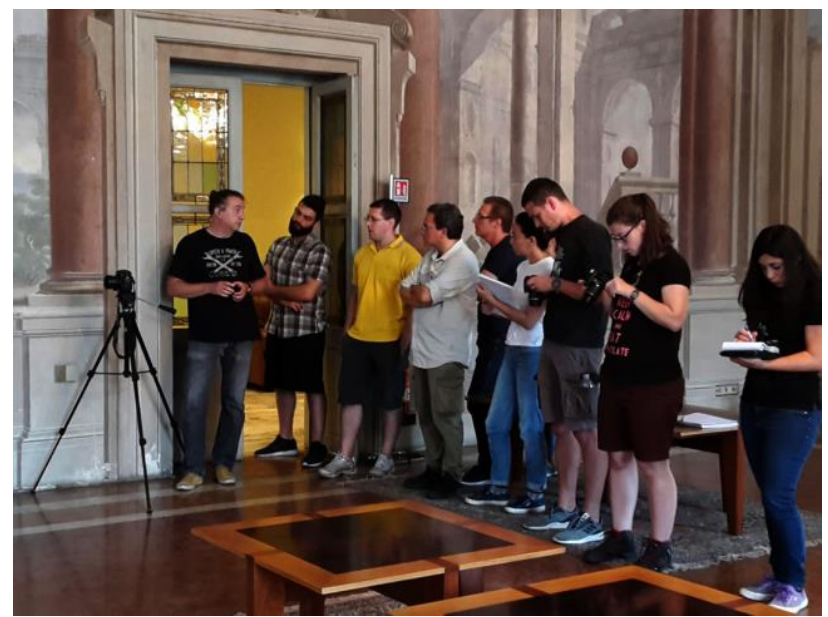

Figure 1. Close-range photogrammetry exercise during GEORES 2017 Preliminary Young Researcher Workshop.

The main aim of these initiatives is essentially social: the active participation of people in projects for cataloguing and

\footnotetext{
* Corresponding author
} 
documentation of local built heritage, also facilitates the construction of the social capital. The participation in cultural heritage events, highlighting the authenticity and uniqueness of its heritage, strengthens the awareness of the community and helps to develop a sense of belonging and to feel themselves as an active part of its safeguard (McCarthy, 2014).

Moreover, considering which results can be obtained with low cost and user-friendly tools in an almost playful way, these initiatives arouse curiosity about new technologies in general and can be used to bring the wider public closer to less-known topics as Geomatics.

Consequently, such initiatives are important even if the data quality is not actually sufficient to achieve the completeness requested, as example, for the reconstruction of monuments destroyed by natural or man-made causes (Vincent, 2017).

These initiatives can use geomatic techniques with different levels of complexity, from simple geotagged 2-D photos to 3-D models generated with photogrammetric Structure-from-Motion techniques on the same device, on the Web or using external software.

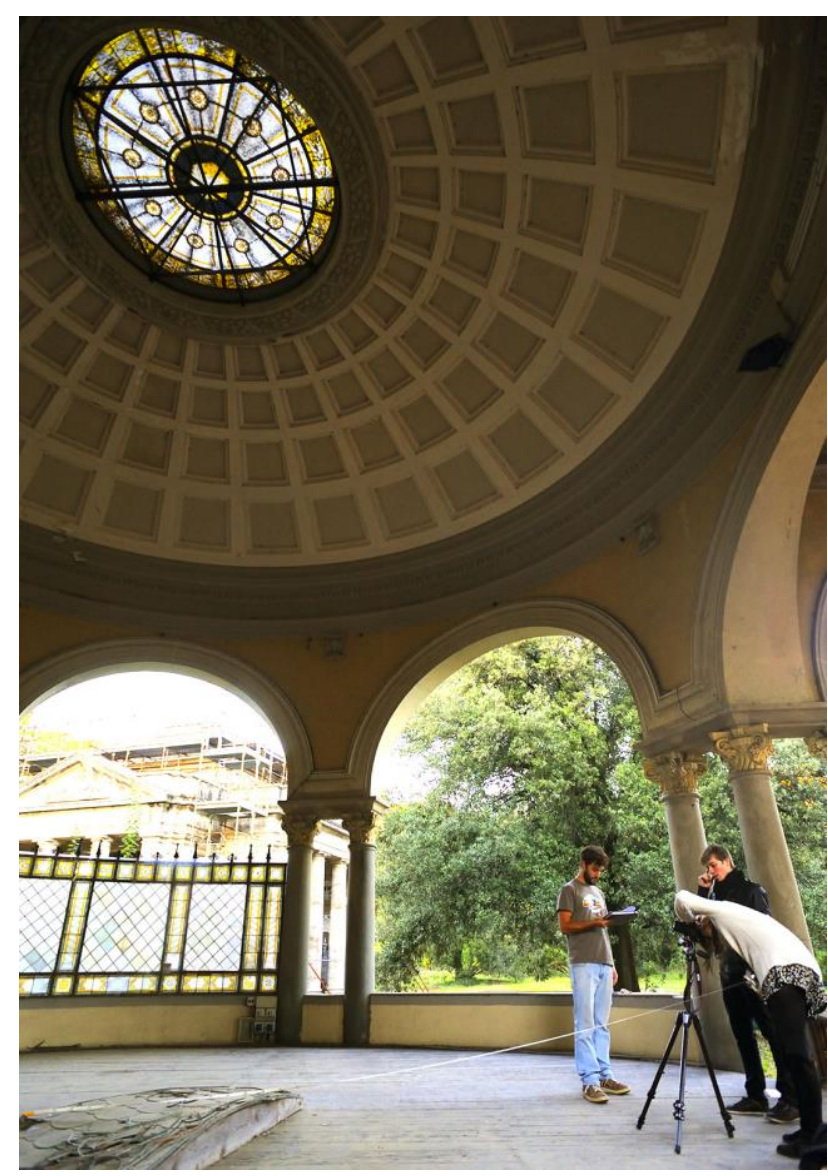

Figure 2. Student's exercise at Montecatini Terme for the "Geomatics for restoration" course, School of Architecture,

University of Florence, 2014.

\section{PHOTOGRAMMETRY FOR EVERYBODY}

\subsection{3-D modelers or photogrammetrists?}

Generally, the SfM photogrammetry has made much more accessible the image-based 3-D reconstruction, allowing the digitalisation of real-world objects by operators which should be more correctly defined as 3-D modelers than photogrammetrists.

Photogrammetry is no longer a topic for specialists only, but it is interesting a very wide audience. Everything physical can be measured and modelled faster, cheaper and in a more detailed way in 2-D, 3-D, 4-D and more.

In opposition to traditional photogrammetry, requiring metric cameras, complex and expensive equipment and specialist expertise, it is possible now to obtain dense point clouds and detailed mesh models with off-the-shelf cameras and userfriendly software (Niederheiser, 2016).

Architects, engineers, archaeologists, geologists and so on have been always interested in measuring and representing the real world and now consider photogrammetry as just another tool for doing it. They are joined now by the new creative industry professionals, as modelers for 3-D printing (Knyaz, 2002) or CG artists which use photogrammetry in movies, videogames and to create VR contents (Statham, 2018).

The spread of UAVs also allows many people to prepare orthophotos and surface models, which until a few years ago could only be performed by expensive and complex cartographic projects carried out by government institutions (Colomina et al, 2014). Obviously, end-users are not aware that behind this simplification there is the complex research performed by experts in photogrammetry and computer vision and software engineering.

\subsection{Get the most out of photogrammetry}

However, the use of photogrammetry by non-specialist users should not be considered only negatively.

This opportunity is even more stimulating given the possibility to not only acquire a geometry but to generate models. A model simplifies the reality to be studied by selecting the most useful characteristics for the use it is designed for.

Photogrammetry involves sampling, which density varies according to the parameters used and the aims of the project. The obtained model is always discrete: it exists a univocal, albeit non-continuous, correspondence between the acquired data and the object, considering any uncertainties regarding the used instruments and procedures.

The subsequent data processing requires to interpolate and interpret this model, according to the aims of the project. The deriving model is continuous and has an analogical verisimilitude with the real object, namely it constitutes a convincing representation of it, insofar as not only it resembles the original object, but it is also validated the theoretical model adopted in the transition from the discrete to the continuous model.

The aspects that the users of photogrammetric models are interested in are certainly geometric, even if with different resolutions and specifications, but also related to many other thematic issues specific for each discipline.

Users attracted by easily obtaining models with these userfriendly devices and workflows are usually professionals from another discipline (like architects, engineers, archaeologists, geologists, agronomists, computer graphic artists), interested in the outcomes but without a specific education and training and so who use them with a mere hands-on approach.

What is happening in photogrammetry is like what has already happened about GIS. Once GIS was the prerogative of a few specialists with a deep understanding of the theory and able to manage the data processing, currently it is used by many operators with skills largely acquired through experience but are still few those who know use it at the best. 
On the other hand, commercial software promotes so efficient automated workflows that only "by pressing a button" users get quite appealing results, at least from its visual impact.

So many end-users think it's enough to get a low cost (or even free) software and use it following fully automatic workflows, at most after reading the quick-start manual, without any awareness and control over what they are doing. Many do not see the need to learn the basics of photogrammetry and possibly don't even recognise that there are any. There is a lack of knowledge of how to do a photogrammetric project correctly and to assess its quality. This can be very harmful if the model is not created for visualization only, but it will be used for conservation or new buildings design. From this point of view, even those who in the past have had a basic knowledge of traditional photogrammetry in their education or professional activity are often unable to understand how the current digital photogrammetry works. The results obtained in this way are often disappointing, and this can conduce to the misleading conclusion that SfM photogrammetry is not suitable for professional applications.

\subsection{Finding a meeting point}

For this reason, it is necessary to increase the awareness of operators, who must understand the principles of photogrammetry, know how to plan a project for obtaining data with the required features, find a workflow tailored for each case study, process data and assess their quality, all aspects that require advanced skills and that cannot be improvised.

On the other hand, in order to properly raise awareness of the quality of spatial data, it is also important that geomatics experts are not involved in the data production workflow only, but also are aware of the aims for which data are produced. Geomatics experts should also know how to produce and interpret models and how to get the required information from the data for each kind of user.

\section{EDUCATION AND TRAINING IN PHOTOGRAMMETRY}

\subsection{Basic training for students and professionals}

The first step towards the dissemination of photogrammetry is therefore that it becomes a basic part of the training of architects, engineers, archaeologists, urban planners, etc. and in general of all the professionals that study the territory and heritage, and their transformations (Hess et al., 2017).

Considering also that they are newly developed tools, the other fundamental aspect is the lifelong learning of previous generations of already active professionals (Acevedo Pardo et al., 2013, Gong et al., 2017).

Obviously, it's not realistic that all professionals will personally use photogrammetry or other geomatic techniques, but it is important to give some basic information also to those who have a managerial role: they must understand what is possible to do, with what means and, ultimately, if they need it.

\subsection{E-learning}

Many researches are aimed at renewing traditional teaching methods. As geomatics is based on the production, processing and dissemination of digital data, it is even more spontaneous than for other fields to rely on E-learning. Among other reasons, this allows to reach more people (both for academic teaching and for life-long education), allows learners to study short educational modules only, helps teachers to exchange data and content with other universities.

The popularity of E-learning in photogrammetry and geomatics is demonstrated by the great number of students attracted by this kind of educational programs. On the other hand, only few of them complete the courses and, the most important thing, online only courses do not provide an effective hands-on training (Vyas et al., 2014).

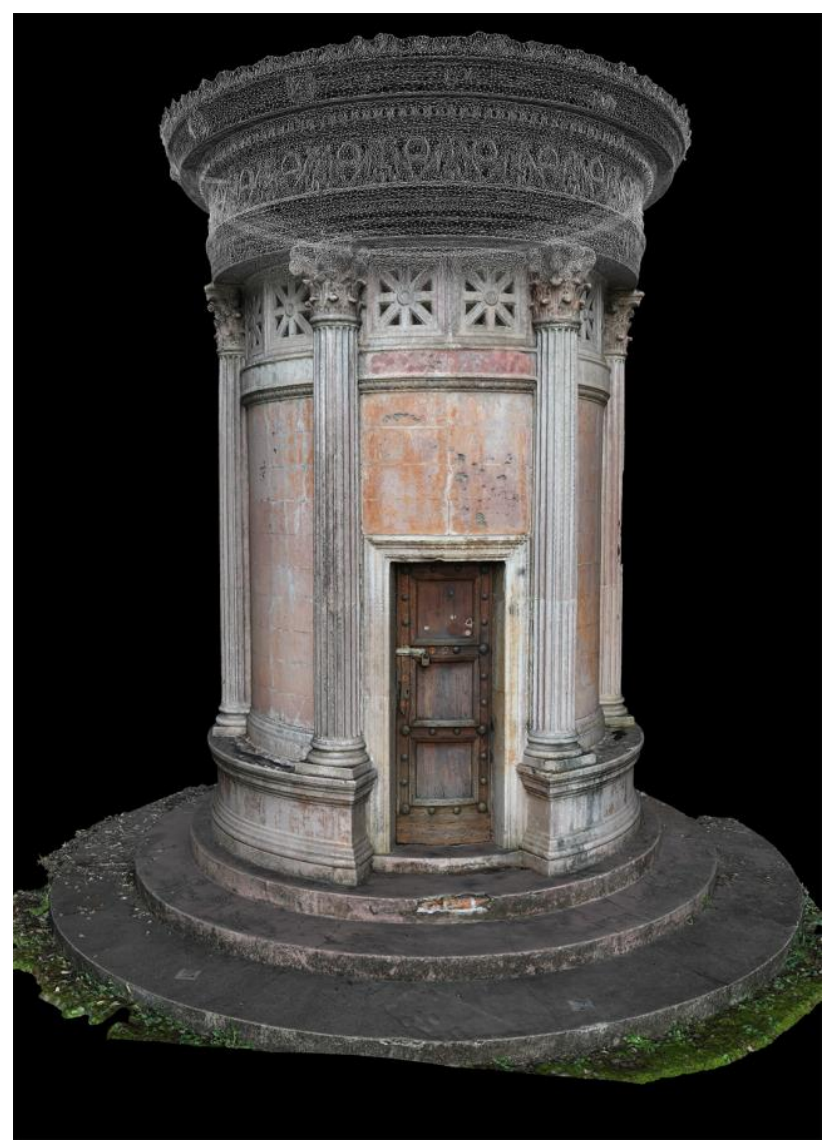

Figure 3. 3-D mesh model of a small heritage building at Terme

Torretta. Student's exercise at Montecatini Terme for the

"Geomatics for restoration" course, School of Architecture,

University of Florence, 2014.

\subsection{Applied photogrammetry}

Our teaching experience is based on the dissemination of photogrammetry, and geomatics in general, for the acquisition of spatial data of the real world.

The focus is often, but not exclusively, on problems relating to cultural heritage, given its abundance in Italy and the importance of its protection and enhancement also for economy and land management.

In our University, since many years photogrammetry and geomatics classes are always "applied" (Tucci et al., 2012), with a strong practical character both within the degree courses for architects and engineers, both in the school of specialization for archaeologists. The same approach is used in the specialization courses, masters and workshops, held in Italy and abroad, as example during the Innova Cuba project (Tucci et al., 2018). These courses are mainly attended by professionals who want to update and deepen their skills because they are aware that they can stand out only using technologies at the best. 
Whether they are university students or professionals already in business, they often have already used photogrammetry software without any specific training.

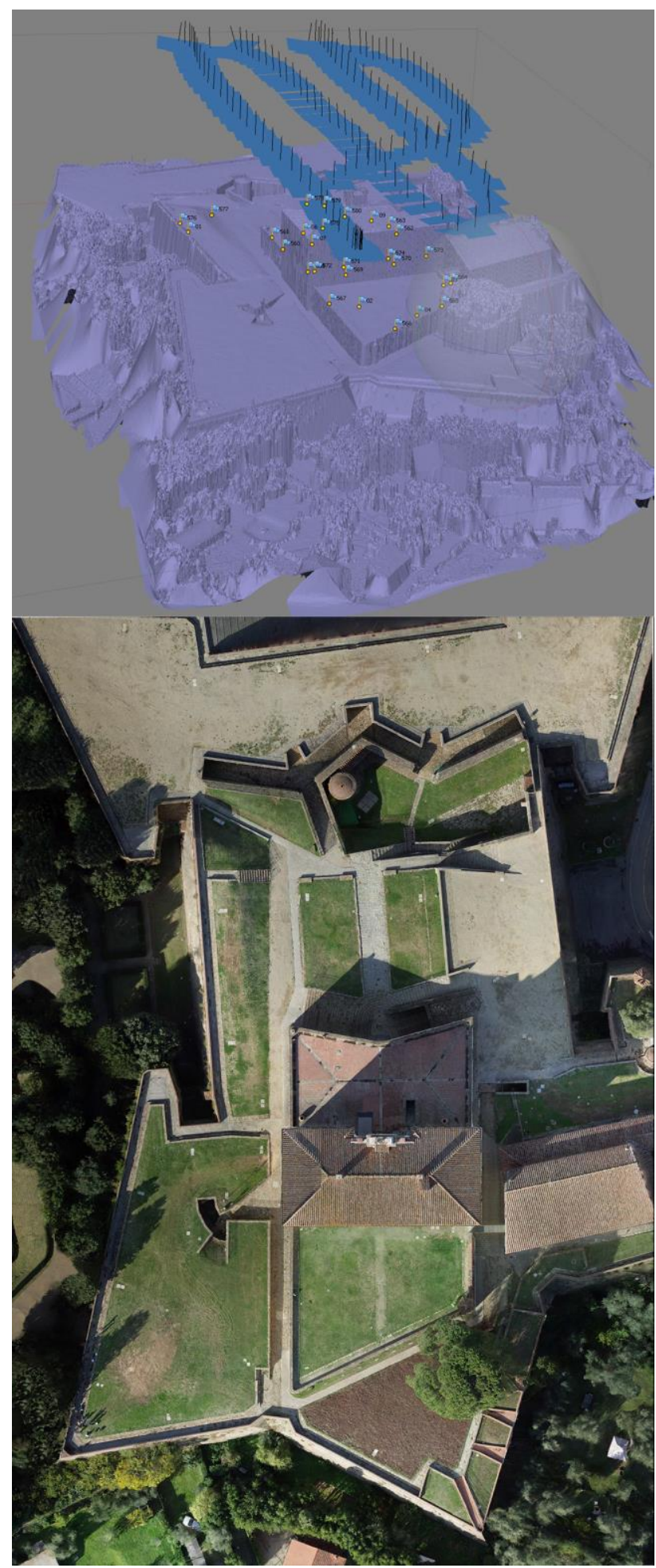

Figure 4. Photogrammetric project (above) and orthophoto (below) of Forte di Belvedere (Florence). Student's exercise for the "Geomatics for restoration" course, School of Architecture, University of Florence, 2016.

\subsection{Learning-by-doing}

The traditional didactic method, in which the teacher gives frontal lessons to explain the theory and later the students carry out exercises on specific aspects of what they are learning, is not very effective because in this case the learners are looking for solutions to fill the gaps in their confused knowledge.

Experiences have shown that an effective form of practical transfer of skills and know-how is that of "learning by doing" or of carrying out projects on specific issues related to local heritage (Kravchenko et al., 2016). Practical experience, together with short lessons that explain the theory behind what they are doing and educational resources that help the students to retrace the steps of what has been proven, is more effective in understanding both the phases of data acquisition and processing but above all in evaluating the quality of data, progressively acquiring the skills necessary to obtain results that are actually useful in their profession and for documentation and conservation of cultural heritage.

The proposed methodology is a "case-based" learning and teaching strategy: the key in utilizing this technique is to capture the imagination of the learners. In this manner students are challenged to learn by doing, develop analytical and decision-making skills, assimilate knowledge, learn how to grapple with real life problems (Kosmatin Fras et al., 2016).

\subsection{Teaching materials for photogrammetry}

Sometimes, however, the conditions of the classes do not give the opportunity to gain experience on all the cases encountered in the professional activity. Lack of time, of suitable case studies or of some of the required equipment, sometimes simply bad weather, are only some of the issues that prevent a complete training being provided (McGovern et al., 2008).

In such cases, it is useful for the teacher to also have teaching materials such as videos, multimedia, datasets on different case studies. These should not be considered as alternative tutorials to a learning guided by a teacher, who instead can focus on how to obtain and verify the quality of results.

Once learners have mastered the correct method under the supervision of a teacher, they can also use these materials for personal study or as an exercise and acquire greater skills also on case studies carried out under conditions different from those present in the place where they live or study.

It is important that the teaching materials should not be software related as far as possible. In this way learners will focus their attention on the principles underlying the photogrammetry. Moreover, in this way materials can be used in many different educational situations and it avoids that they will be interpreted once again only as tutorials for learning a specific software.

Another issue is that during field operations there are many practical aspects that can improve the overall quality of the photogrammetric project, e.g. camera settings and positioning, photographic technique, illumination, props and so on. Although these skills can be learned in the most effective way only during on the field supervised workshops, videos can be very useful to remind learners of the best practice in many different conditions.

For all these purposes, it would be important for the most sensitive to training and education part of the ISPRS community to be involved in producing and sharing teaching materials on these topics.

A step could be the project "Education and training resources on digital photogrammetry", held together with Anjana Vyas (CEPT University), Vikram Sorathia (Kensemble Tech Labs), Satwant Rihal (California Polytechnic State University) and 
financed in 2018 by ISPRS as part of the "Educational and Capacity Building Initiative" programme, it provides for preparing and sharing some videos about digital photogrammetry, above all focused on the optimal photogrammetric set-up, both in case of close-range and UAVs photogrammetry, notably for projects aimed to cultural heritage documentation, structural and seismic performance assessment and support to conservation projects.

The aim of the project is to make some videos about:

a close range photogrammetric project optimal setup;

an UAV-based photogrammetric project optimal setup;

the role of control measurement in a photogrammetric project.

The planned steps are:

to produce digital images and 3-D models describing a digital camera and its intrinsic and extrinsic parameters;

to collect digital images to explain the main photographic issues useful in photogrammetry - image exposure, depth of field, etc.;

to film and shoot people working on the field, taking photos for photogrammetric purposes following an appropriate project planning - for buildings, small objects, using UAVs and so on;

- $\quad$ to edit some videos/multimedia on the above-mentioned topics;

acquire 3-D data (a reference 3-D model by laser scanning, imagery and ground control points, photogrammetric outcomes examples, etc.) on case studies with different features that may illustrate situations frequently in the field work;

to arrange the dataset and to publish it in the ISPRS web site, Education, Data sets section;

to publish videos and multimedia resources in the ISPRS web site, Education, Tutorial section.

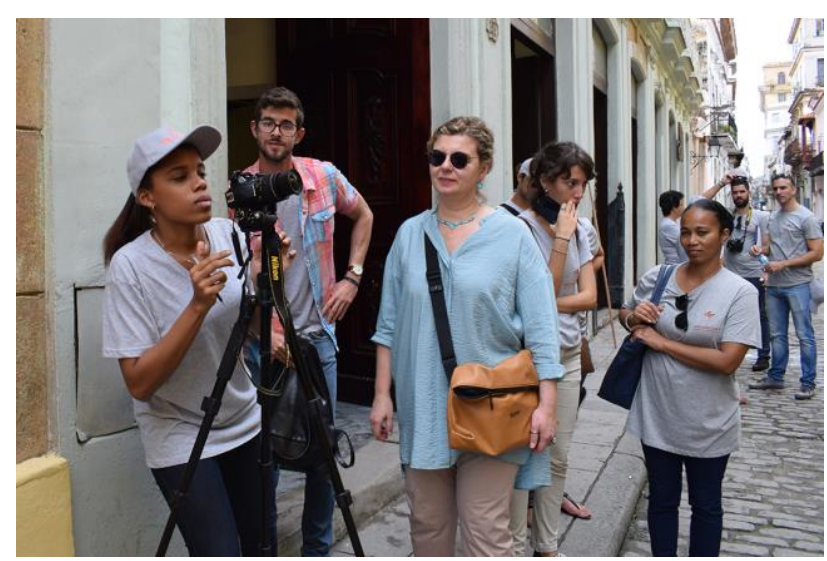

Figure 5. An example of life-long education experience: handson photogrammetry workshop in Havana during the Innova Cuba project, 2018.

\section{CONCLUSIONS}

Compared to traditional lecture method, it is considered that the learning-by-doing method is more effective in teaching photogrammetry in a wide range of non-specialist courses and in disseminating among those who already are using it not being aware of its principles and correct use. In this way learners can focus on how to achieve the best quality and assess the accuracy of results working on real case studies. To allow teachers to present a wider range of cases, we propose the creation and dissemination of teaching materials (video and dataset) available to the ISPRS community.

\section{REFERENCES}

Acevedo Pardo, C., Farjas, M., Georgopoulos, A., Mielczarek, M., Parenti, R., Parseliunas, E., Schramm, T., Skarlatos, D., Stefanakis, E., Tapinaki, S., Tucci, G. Zazo, A., 2013. Experiences gained from the Erasmus intensive programme HERICT 2013. In: CERI2013. Conference Proceedings, IATED, pp. 4424-4431. ISBN: 978-84-616-3847-5

[online: http://library.iated.org/view/acevedopardo2013exp $(14 / 10 / 2018)]$

Agarwal, S., Snavely, N., Simon, I., Seitz, S. M., Szeliski, R., 2009. Building Rome in a day. In: Computer Vision, 2009 IEEE 12th International Conference on, pp. 72-79.

Colomina, I., Molina, P., 2014. Unmanned aerial systems for photogrammetry and remote sensing: A review. ISPRS Journal of Photogrammetry and Remote Sensing, 92, pp. 79-97. doi.org/10.1016/j.isprsjprs.2014.02.013

Gilliéron P.-Y., Vincent, G., Merminod, B., 2015. Blending a MOOCs with Interactive Teaching. FIG Working week 2015 From the Wisdom of the Ages to the Challenges of the Modern World. 7703.

Gong, J., Yue, P., Woldai, T., Tsai, F., Vyas, A., Wu, H., Gruen, A., Wang, L., Musikhin, I., 2017. Geoinformatics education and outreach: looking forward. Geo-spatial information science, 20(2), pp. 209-217.

doi.org/10.1080/10095020.2017.1337319

Hess, M., Garside, D., Nelson, T., Robson, S., Weyrich, T. 2017. Object-based teaching and learning for a critical assessment of digital technologies in arts and cultural heritage. In: The International Archives of the Photogrammetry, Remote Sensing and Spatial Information Sciences, Vol. XLII-2/W5, pp. 349-354.

doi.org/10.5194/isprs-archives-XLII-2-W5-349-20

Knyaz, V. A., 2002. Photogrammetry for rapid prototyping: development of noncontact 3D reconstruction technologies. Proc. SPIE 4644, Seventh International Conference on Laser and Laser-Information Technologies. 4644, pp. 414-422; doi.org/10.1117/12.464174

Kosmatin Fras, M., Grigillo, D., 2016. Implementation of active teaching methods and emerging topics in photogrammetry and remote sensing subjects. In: The International Archives of the Photogrammetry, Remote Sensing and Spatial Information Sciences, Vol. XLI-B6, pp. 87-94.

doi.org/10.5194/isprsarchives-XLI-B6-87-201

Kravchenko, I., Luhmann, T., Shults, R. 2016. Concept and Practice of Teaching Technical University Students to Modern Technologies of 3d Data Acquisition and Processing: a Case Study of Close-Range Photogrammetry and Terrestrial Laser Scanning. In: The International Archives of the Photogrammetry, Remote Sensing and Spatial Information Sciences, Vol. XLI-B6, pp. 65-69.

doi.org/10.5194/isprsarchives-XLI-B6-65-20

Letellier, R., 2015. Recording, documentation and information management for the conservation of heritage places. Routledge, London/New York 
McCarthy, J., 2014. Multi-image photogrammetry as a practical tool for cultural heritage survey and community engagement. Journal of Archaeological Science 43 pp. 175-185. doi.org/10.1016/j.jas.2014.01.010

Niederheiser, R., Mokroš, M., Lange, J., Petschko, H., Prasicek, G., Elberink, S. O. 2016. Deriving 3D point clouds from terrestrial photographs - Comparison of different sensors and software. In: The International Archives of the Photogrammetry, Remote Sensing and Spatial Information Sciences, Vol. XLI-B5, pp. 685-692. doi.org/10.5194/isprsarchives-XLI-B5-685-20

Statham, N. 2018. Use of photogrammetry in video games: a historical overview. Games and Culture doi.org/10.1177/1555412018786415

Teo, T. A., Wu, H. M., Shih, T. Y., Tsai, F., 2014. The analysis of smartphone apps in geomatics education. In: The International Archives of the Photogrammetry, Remote Sensing and Spatial Information Sciences, Vol. XL-6, pp. 93-97. doi.org/10.5194/isprsarchives-XL-6-93-20

Tucci G., Bonora V. 2009, Teaching Geomatics, In: Proceedings of the XXII CIPA International Symposium "Digital Documentation, Interpretation \& Presentation of Cultural Heritage", Kyoto, Japan, October 11-15 2009, pp. 1682-1777

Tucci, G., Conti. A., Fiorini, L., Mei, F., Parisi, E.I., Digital photogrammetry as a resource for Cuban cultural heritage: educational experiences and community engagement within the Innova Cuba project. In: The International Archives of the Photogrammetry, Remote Sensing and Spatial Information Sciences, forthcoming.

Vincent, M. L., 2017. Crowdsourced data for cultural heritage. In: M.L. Vincent et al. (eds.), Heritage and Archaeology in the Digital Age, Quantitative Methods in the Humanities and Social Sciences, Springer, Cham, pp. 79-91. doi.org/10.1007/978-3-319-65370-9_5

Vyas, A., Koenig, G., 2014. Computer Aided Teaching in Photogrammetry, Remote Sensing, and Geomatics - A Status Review. In: The International Archives of the Photogrammetry, Remote Sensing and Spatial Information Sciences, Vol. XL-6, pp. 113-118.

doi.org/10.5194/isprsarchives-XL-6-113-20

Vyas, A., König, G., 2016. E-learning in photogrammetry, remote sensing and spatial information science. In: The International Archives of the Photogrammetry, Remote Sensing and Spatial Information Sciences, Vol. XLI-B6, pp. 45-52. doi.org/ 10.5194/isprsarchives-XLI-B6-45-20 